Ramey, M. M., Shields, G. S., \& Yonelinas, A. P. (2020). Markers of a plant-based diet relate to memory and executive function in older adults. Nutritional Neuroscience, 1-10.

\title{
Markers of a plant-based diet relate to memory and executive function in older adults
}

Michelle M. Ramey, M.A. ${ }^{1,2^{*}}$ Grant S. Shields, Ph.D. ${ }^{1}$ Andrew P. Yonelinas, Ph.D. ${ }^{1}$

${ }^{1}$ Department of Psychology and Center for Neuroscience, University of California, Davis, CA, 95616.

${ }^{2}$ Center for Mind and Brain, University of California, Davis, CA, 95618.

*Corresponding author: Michelle M. Ramey, Department of Psychology, University of California, Davis, CA, 95616. Email: mmramey@ucdavis.edu. 


\begin{abstract}
Background: Although it is widely known that consumption of plant-based foods is important for physical health, little is known about the relationship between plant-based foods and cognitive health. Emerging evidence suggests that some macronutrients may exert effects on cognition, but it is unclear which domains of cognition are involved; more importantly, it is unknown how a plant-based dietary pattern relates to cognition.
\end{abstract}

Objective: To examine associations between a plant-based dietary pattern and multiple cognitive functions (i.e., memory and two aspects of executive function).

Methods: Participants were 3,039 older adults who participated in the 2011-2014 waves of the National Health and Nutrition Examination Survey (NHANES). The present crosssectional study used data on macronutrient intake from two 24-hour dietary interviews, as well as performance on tests of long-term memory and executive function (i.e., delayed word recall, digit symbol substitution test, and animal fluency). Principal component analysis was used to extract a dietary pattern consistent with a plant-based diet.

Results: Greater adherence to a dietary pattern consistent with a plant-based diet was related to better performance on all cognitive tasks. Secondary analyses indicated that the associations between a plant-based dietary pattern and executive function accounted for the association between a plant-based dietary pattern and memory. Furthermore, this same plantbased dietary pattern was associated with reduced baseline inflammation in a separate dataset.

Conclusions: Experimental manipulations are needed to determine the direction and timescale of the observed associations, but these results suggest that a plant-based diet is related to better cognition, especially through improved executive control. Future work should also 
attempt to extend these results by examining potential mechanisms underlying these associations, such as reduced inflammation.

Keywords: Diet; Memory; Executive function; Nutrition; Vegan diet; Older adults; NHANES;

Aging; Plant-based diet 


\section{Introduction}

Diet-related diseases such as obesity, cardiovascular diseases, type 2 diabetes and cancer have become a leading cause of death in the United States (1-4). However, some interventions have seen success with treating diet-related diseases. In particular, adherence to a plant-based diet - that is, a diet primarily based on foods derived from plants such as vegan, vegetarian, pescovegetarian, and semi-vegetarian diets (5) — has been shown to reduce or eliminate the need for medication in type 2 diabetes, produce faster weight loss than standard weight-reducing diets in people with obesity, and reduce biomarkers of cardiovascular disease risk (6-10). Although the evidence points to a benefit of plant-based diets for physical health, it is not known how plant-based diets might relate to cognition.

Multiple studies have established that adherence to a plant-based diet is characterized by low saturated fat and protein intake, and high fiber and polyunsaturated fat intake $(5,11,12)$. Although no study to our knowledge has examined how a plant-based diet affects cognition, some studies have examined how individual macronutrients - some relevant to plant-based diets—relate to cognition. In particular, although adding protein beyond the minimum requirement does not appear to influence cognition $(13,14)$, variations in the remaining macronutrients characteristic of plant-based diets do appear to relate to cognition. That is, higher saturated fat intake generally predicts or relates to worse cognitive function, whereas higher intakes of polyunsaturated fat and fiber generally predict or relate to better cognitive function (15-21). Therefore, intake of individual macronutrients consistent with a plant-based diet is related to better cognition, suggesting that plant-based diets in general may be related to better cognition. 
However, two issues remain open. First, as mentioned above, it is unknown how these macronutrients relate to cognition when considered together. That is, because different types of foods contain distinct profiles of macronutrients and micronutrients, examining macronutrients in isolation may obscure effects that would otherwise arise from overall patterns of food consumption. Second, most studies of individual macronutrients related to plant-based diets are unclear on which cognitive domains are involved; most studies have used either a single cognitive outcome, or, more commonly, a single measure of global cognition (e.g., the MiniMental State Examination; (22)). In sum, it is currently unknown whether a holistic consumption pattern consistent with a plant-based diet might be associated with cognition, or which domains of cognition may be involved.

Understanding the specific cognitive domains that may be affected by plant-based diets has particularly notable implications for some populations, such as older adults. First, improving memory in individuals at high risk of developing dementia may slow or help prevent cognitive decline in those individuals (23). Even in older adults without risk of pathological cognitive decline, there exist specific physical health issues that may be remediated by better cognitive health. For example, better executive functioning predicts better medication adherence (24) and a smaller risk of falling in older adults (25), both of which are strong contributors to physical health in older adults. In short, determining the specificity of the diet-cognition relationship could help design targeted interventions for populations with specific cognitive health needs, such as older adults.

\section{Current Research}

The present cross-sectional study aimed to address the question of whether macronutrient intake characteristic of a plant-based diet is naturally present in older adults, and whether this 
dietary pattern is associated with performance on distinct cognitive tasks: namely, one task that assesses long-term memory, and two tasks that assess different aspects of executive functioning. We hypothesized that a dietary pattern consistent with a plant-based diet would relate to better performance on the memory and executive function tasks.

\section{Methods}

\section{Participants}

Data were obtained from the 2011-2014 National Health and Nutrition Examination Survey (NHANES), conducted by the National Center for Health Statistics under the CDC. The survey collects cross-sectional nutrition and health information from a nationally representative, civilian, non-institutionalized population using in-home interviews and questionnaires as well as mobile centers for physical examinations (26). Participants $\left(N=3,039 ; 1,465\right.$ female; $M_{\text {age }}=$ $69.79, S D_{\text {age }}=6.88$, range $\left.=60-80\right)$ included in the analyses were those who completed the dietary assessment, though some participants did not complete all cognitive tasks; of the 3,039 participants, 211 had missing recall data, 286 had missing digit symbol data, and 224 had missing fluency data. In total, 2,655 participants had complete data for every variable examined, including covariates ${ }^{1}$. Of the sample, $47.6 \%$ identified as non-Hispanic White, $24.2 \%$ as nonHispanic Black, 8.9\% as Mexican American, 9.8\% as Other Hispanic, 8.0\% as non-Hispanic Asian, and $1.6 \%$ as Other (including multi-racial). This analysis of secondary data was approved by the local university IRB.

\section{Materials and Procedure}

To assess the relation between nutrient intake and cognitive performance, we examined both cognitive and dietary variables from the included NHANES waves. Executive function was

\footnotetext{
${ }^{1}$ Note that the results were equivalent regardless of whether or not analyses were restricted to participants with complete data.
} 
assessed using the animal fluency test and the digit symbol substitution test, whereas memory performance was assessed using the CERAD word learning test; detailed descriptions of these measures are provided in the following paragraphs. For further information regarding these tasks, please see the descriptions from the CDC (27).

Animal fluency measures categorical verbal fluency, which is considered to be an executive function (27-29). Participants were given one minute to name as many animals as they could, and a point was given for each unique named animal.

The digit symbol substitution test relies primarily on sustained attention and processing speed, along with contributions from working memory $(27,30)$. The task requires participants to use a legend - pairing nine numbers with symbols — to match 133 numbers with their corresponding symbols within two minutes. Participants were scored on how many correct matches were made within the two-minute time limit.

The Consortium to Establish a Registry for Alzheimer's Disease (CERAD) word learning subtest includes both immediate and delayed memory tests for verbal information. Despite having been developed for individuals with dementia, similar prior studies have found that the CERAD successfully assesses memory performance in individuals without dementia as well (31). During learning trials, 10 words were spoken aloud by the experimenter, one at a time; in the recall tests, the participants were asked to recall as many of the 10 words as they could recall. Three learning trials and the immediate recall test were completed prior to the fluency task and digit symbol substitution test, whereas the delayed recall test was completed 8-10 minutes after initial learning. Performance on the delayed recall test was scored as the number of words recalled out of the 10 studied words. 
Dietary interviews conducted on two separate days assessed nutrient intakes over each preceding 24-hour period. The cognitive tasks were completed during the same session as the first dietary interview. The primary diet variables of interest were participants' average consumption of saturated fat, polyunsaturated fat, fiber, protein, and calories.

\section{Statistical analysis}

Dietary variables were skewed, and were square root transformed such that they conformed to a normal distribution.

Principal component analysis (PCA) was used to confirm that participants' macronutrient consumption naturally varied along a dietary spectrum ranging from consistent with high intake of plant-based foods (high intake of fiber and polyunsaturated fat) and low intake of animalbased foods (low intake of saturated fat and protein), to the opposite pattern. PCA is a dimensionality reduction technique that is used to extract important patterns by representing the data as a set of orthogonal variables that maximally capture variation in the data (32). The resulting variables are known as components, which are statistically independent and ordered according to the amount of variation they explain (i.e., the first principal component explains more variation in the data than does the fourth component). The macronutrient variables that were included in the PCA were saturated fat, polyunsaturated fat, fiber, and protein; each was divided by calories consumed to normalize them with respect to total intake. The goal of the PCA was to produce a score for each participant, with higher scores reflecting consumption of a diet more indicative of a plant-based diet.

Linear regression was used to assess the relation between the plant-based scores obtained using the principal component analysis and the cognitive variables. The models included the recommended dietary weights provided by NHANES to increase the representativeness of the 
data with regards to the U.S. population. We averaged between the weights provided for the day 1 and day 2 dietary recall interviews, as macronutrient information from both days were used in analysis. Demographic variables relevant to diet or cognition served as covariates — namely age, sex, education, and body mass index (BMI). In addition, to ensure that any effects observed with the plant-based principal component were not driven by overall healthier behaviors, we used covariates of positive and negative health behaviors (i.e., minutes exercised over the past week, cigarettes consumed per day on average, and excessive alcohol consumption $[>5$ drinks/day or $>15$ drinks/week for men; $>4$ drinks/day or $>8$ drinks/week for women]). Our covariates were selected based upon prior literature that had noted associations of each of these variables with both diet and cognitive measures (28,29,33-38).

When a null result was obtained, evidence for the null was quantified with Bayesian analyses using the BayesFactor package, version 0.9.12-4.2 in R, version 3.5.0. For ease of interpretation, Bayes factors were inverted (i.e., $\mathrm{BF}_{01}=1 / \mathrm{BF}_{10}$ ) such that higher values indicate greater evidence for the null. By convention, a Bayes factor $\mathrm{BF}_{01}$ greater than 3.16 indicates substantial evidence in favor of the null hypothesis (39).

\section{Results}

Table 1 presents descriptive statistics and correlations for the variables of interest. The participants' performance on the cognitive tasks was similar to norms established in healthy older adult populations, falling within one standard deviation of the established means $(34,40,41)$. Total calories consumed were controlled for to allow us to assess macronutrient intakes relative to total intake, given that macronutrient intakes were given in grams (42). 
Table 1. Descriptive Statistics for Primary Variables and Covariates of Interest, and Associations with Cognitive Outcomes

\begin{tabular}{|c|c|c|c|c|c|c|}
\hline \multirow[b]{2}{*}{ Variable } & \multirow[b]{2}{*}{ Range } & \multirow[b]{2}{*}{ Mean } & \multirow[b]{2}{*}{$S D$} & \multicolumn{3}{|c|}{ Association with Other Variables } \\
\hline & & & & Recall & DSST & Fluency \\
\hline Age & $60-80$ & 69.79 & 6.88 & $-.30 * * *$ & $-.29 * * *$ & $-.23 * * *$ \\
\hline BMI & $13.4-82.1$ & 29.03 & 6.36 & $.06 * *$ & .01 & $.04^{*}$ \\
\hline Recall & $0-10$ & 5.85 & 2.38 & - & - & - \\
\hline DSST & $0-105$ & 46.01 & 17.31 & $.47 * * *$ & - & - \\
\hline Fluency & $1-40$ & 16.51 & 5.54 & $.40 * * *$ & $.51 * * *$ & - \\
\hline Calories & $156-5679$ & 1801.18 & 690.70 & $.06 * *$ & $.10 * * *$ & $.10 * * *$ \\
\hline SFA & $0.71-87.21$ & 21.65 & 11.60 & $-.05 *$ & -.03 & $-.06 * *$ \\
\hline PUFA & $0.86-70.06$ & 16.41 & 9.08 & $.04 *$ & $.05 * *$ & $.05^{*}$ \\
\hline Fiber & $0.15-118.4$ & 16.82 & 9.17 & .02 & .00 & $.06 * *$ \\
\hline Protein & $5.2-234.94$ & 72.19 & 30.03 & .04 & .03 & $.04 *$ \\
\hline PB score & $-5.27-4.14$ & 0.00 & 1.00 & $.04 *$ & $.05 * *$ & $.06 * *$ \\
\hline
\end{tabular}

$\overline{\text { Note: } * p<.05, * * p<.01, * * * p<.001 . \text { DSST }=\text { Digit symbol substitution test; Fluency }}$ $=$ Animal fluency; SFA = Saturated fatty acids; PUFA = Polyunsaturated fatty acids; PB score $=$ Plant-based score. Demographic statistics are provided for those participants who completed the dietary recall $(N=3039)$. Partial correlation values are provided for the associations between the macronutrients (i.e., SFA, PUFA, fiber, protein) and the cognitive variables, controlling for calorie intake and relevant demographic variables, and using the recommended dietary weights provided by NHANES. Associations with SFA and PUFA also control for total fat intake, and associations with calories control 
for relevant demographic variables.

In the principal component analysis, the expected dietary pattern (high polyunsaturated

fat and fiber, low saturated fat and protein) emerged as the second of four principal components: ${ }^{2}$ the loadings were .73 for polyunsaturated fat, .27 for fiber, -.29 for saturated fat, and -.56 for protein, such that higher scores were more consistent with a plant-based diet. This component explained $25 \%$ of the variance in the macronutrient data. A chi-square goodness of fit test showed that even the first three components were not sufficient to explain the variance in intake patterns of these macronutrients $\left(\chi^{2}=659.06, p<.001, \mathrm{RMSE}=.13\right)$, indicating that all four components were necessary to explain the variance in macronutrient intake. Therefore, this indicates that the plant-based principal component (i.e., the second principal component) was a necessary component in explaining the data; that is, without the plant-based component, the ability of the principal component analysis to explain the variance in the macronutrient data would drop significantly. This indicates that a pattern consistent with a plant-based diet—based on prior findings that a plant-based diet is low in protein and saturated fat, and high in polyunsaturated fat and fiber $(5,11,12)$ - was naturally present in the sample. ${ }^{3}$

To assess whether a dietary pattern consistent with a plant-based diet was associated with cognitive performance, scores on the plant-based component (i.e., plant-based scores) yielded by the principal component analysis were then related to performance on the recall, animal fluency,

${ }^{2}$ The loadings for fiber, saturated fat, polyunsaturated fat, and protein, respectively, for PC1 were -.64, .64, .26, .31 ; for PC3 they were $-.08, .04, .63, .77$; and for PC4 they were $.71, .71, .03, .12$. The principal components were not rotated with an oblique transformation, and as such were uncorrelated, $|r| \mathbf{s}<.001, p \mathrm{~s}>.999$, entailing that our second component could be examined independently of the others. Although they were not relevant to our a priori hypotheses, in the interest of completeness, the associations between the other principal components and the cognitive tasks were as follows. PC1 (high fat, low fiber and protein) was unrelated to any cognitive task, $p \mathrm{~s}>.294$. Interestingly, according to prior work, the macronutrient profile of $\mathrm{PC} 1$ was consistent with a dietary spectrum ranging from highly processed to unprocessed foods (67). PC3 (high polyunsaturated fat and protein, negligible fiber and saturated fat) was related to better performance on all cognitive tasks, $\beta \mathrm{s}>.07, p \mathrm{~s}<.001$; and PC4 (high fiber and saturated fat, negligible loadings of polyunsaturated fat and protein) was weakly related to digit symbol and fluency performance, $\beta \mathrm{s}<.05, p \mathrm{~s}>.016$, and unrelated to recall, $\beta<.01, p=.609$.

${ }^{3}$ It should be noted, though, that our data cannot address the possibility that additional dietary choices may have resulted in a consumption of this macronutrient profile. 
and digit symbol substitution tasks. Higher plant-based scores were associated with better performance on each of these cognitive variables (see Figure 1): plant-based scores were positively associated with recall performance, $\beta=.07, p<.001$, and this held when controlling for covariates of age, sex, education and body mass index, although the effect size was reduced to about two thirds of what it had been, $\beta=.04, p=.022$. Similarly, plant-based scores were also associated with digit symbol substitution performance, $\beta=.08, p<.001$, and these associations held with covariates, $\beta=.04, p=.004$. Lastly, plant-based scores were associated with better performance on the fluency task, $\beta=.08, p<.001$, which also held with covariates, $\beta=.06, p=.002 .{ }^{4}$ Furthermore, additional analyses indicated that all of these effects held when additional healthrelated covariates (i.e., cigarette smoking, exercise, and excessive alcohol consumption) were added to the model containing the covariates of age, sex, education, and body mass index, $p s<.025$. Therefore, greater adherence to a dietary pattern consistent with a plant-based diet is related to better memory and executive functioning.

\footnotetext{
${ }^{4}$ Although education is sometimes used as a measure of socioeconomic status, for the sake of completeness, we also re-ran the analyses including income (i.e., ratio of family income to poverty level) as a covariate as well. All results held, $p s<.023$.
} 
associated with recall when either or both of the other tasks (i.e., the executive function tasks) were covaried, $p s \geq .17$, the relation with plant-based score held for both the digit symbol substitution and fluency tasks with recall covaried out, $p s \leq .025$ (Table 2). Furthermore, the relation between plant-based score and fluency was most robust, as they remained significantly associated regardless of which tasks were covaried, $p s \leq .036$. The results of this analysis suggest that plant-based scores may specifically be associated with executive function, and their relation with memory may be due to the underlying executive function components that recall draws on, such as generation (assessed by the fluency task) and processing speed (assessed by the digit symbol substitution ask) (29). Furthermore, plant-based scores may be most related to processes underlying verbal fluency.

Table 2. Relation Between Cognitive Tasks and Plant-Based Scores When Controlling for Other Cognitive Tasks

\begin{tabular}{|c|c|c|c|c|c|c|c|c|}
\hline Covariates: & \multicolumn{2}{|c|}{ Recall } & \multicolumn{2}{|c|}{ DSST } & \multicolumn{2}{|c|}{ Fluency } & \multicolumn{2}{|c|}{ Other 2 tasks } \\
\hline Outcome & $\beta$ & $p$ & $\beta$ & $p$ & $\beta$ & $p$ & $\beta$ & $p$ \\
\hline Recall & - & - & .02 & .19 & .02 & .17 & .01 & .39 \\
\hline DSST & .03 & .02 & - & - & .02 & .10 & .02 & .17 \\
\hline Fluency & .05 & $<.01$ & .04 & .02 & - & - & .03 & .04 \\
\hline
\end{tabular}

Table 2. Beta and $p$ values for linear models relating plant-based scores to cognitive task performance, covarying out one or both of the other cognitive tasks. Covariates are listed by column, whereas outcomes are listed by row. Models controlled for BMI, age, sex, and 
education, and included the dietary weights provided by NHANES. DSST $=$ Digit symbol substitution test.

\section{Secondary Analyses}

\section{Monounsaturated fat}

Studies of the Mediterranean diet—a dietary pattern that shares some commonalities with a plant-based diet — have suggested that monounsaturated fat is a primary factor in the health benefits of the diet $(43,44)$. We sought to determine whether monounsaturated fat might be related to cognitive performance as well. The relation between monounsaturated fat intake and the three cognitive outcomes was assessed using linear models with relevant demographic covariates (i.e., BMI, age, sex, education), as well as covariates for calories and total fat intake to assess monounsaturated fat intake in relation to total intake. Associations were nonsignificant between monounsaturated fat and recall $(\beta=.025, p=.70)$, monounsaturated fat and digit symbol substitution $(\beta=-.014, p=.80)$, and monounsaturated fat and fluency $(\beta=.08, p=.24)$. In Bayesian implementations of the same models as above, Bayes factors indicated substantial evidence for the null for recall $\left(\mathrm{BF}_{01}=8.08\right)$ and digit symbol substitution $\left(\mathrm{BF}_{01}=8.85\right)$, and inconclusive evidence for fluency $\left(\mathrm{BF}_{01}=.94\right)$. For comparison, the equivalent analyses were carried out with polyunsaturated fat as the independent variable in place of monounsaturated fat: unlike monounsaturated fat intake, polyunsaturated fat intake was significantly associated with better performance on each cognitive task (recall: $\beta=.07, p=.041$; digit symbol substitution: $\beta=.08$, $p=.008$; fluency: $\beta=.09, p=.013$ ). Taken together, this suggests that there is evidence against—or in the case of fluency, no evidence in support of - monounsaturated fat intake being related to memory or executive function. 


\section{Inflammation}

It has been suggested that the effects of diet on both physical and cognitive health may be mediated in part by changes in inflammation (45-48). To examine this, we carried out a secondary analysis to investigate whether a plant-based dietary pattern was associated with a lower level of baseline inflammation. The waves of NHANES that contained cognitive data (2011-2014) did not include measures of inflammation; therefore, only data from the 2007-2010 waves (which do not have cognitive measures) were used to examine the relation between plantbased scores and inflammation. The outcome of interest was levels of C-reactive protein (CRP) - an acute phase protein synthesized by the liver in response to multiple inflammatory factors, making it an excellent indicator of overall inflammation (49)—which was log transformed to reduce skewness. The CRP data was collected during the same assessment session as the first dietary interview. The loadings acquired from the principal component analysis, as described above, were used to create plant-based scores for the inflammation dataset. A linear model relating plant-based scores and CRP with covariates of BMI, age, sex, and education showed that a higher plant-based score was associated with significantly lower levels of CRP, $\beta=-.03, p<.001$. Thus, greater adherence to a dietary pattern consistent with a plantbased diet was related to lower levels of systemic inflammation in these data.

\section{Discussion}

The results of the present study show that a dietary pattern consistent with a plant-based diet was related to better performance in two executive function tasks and one long-term memory task. These findings therefore suggest that a more plant-based diet relates to better cognition in terms of both memory and executive function in older adults. Furthermore, the results of secondary analysis suggest that a plant-based diet may be particularly related to executive 
function, which may underlie the associations observed with both executive tasks and free recall. Future studies using additional cognitive tasks will be useful in determining the specificity of the cognitive domains that may be related to a plant-based diet.

One possible mechanism that could have been thought to underlie the present results is BMI: plant-based diets reduce BMI, and lower BMI has been associated with better cognitive function $(6-8,28)$. The associations observed in the present study were stronger without controlling for BMI, but they still held with BMI as a covariate, which indicates that diet is also associated with cognition independently of BMI. Another possible mechanism linking diet and cognition is inflammation; specifically, inflammation has been shown to mediate the impairing effects of saturated fat on memory in rodents (50). Furthermore, consumption of both fiber and polyunsaturated fat is related to lower inflammation, whereas meat consumption predicts or is related to higher inflammation (46-48). It is therefore possible that some effects of plant-based diets on health (6-10) and cognition could be mediated in part by inflammation. This hypothesis is consistent with the results of one of our secondary analyses, which revealed that a higher plant-based score was related to lower baseline inflammation. Importantly, though, because data on cognitive task performance and inflammation markers were not collected for the same subjects in the National Health and Nutrition Examination Survey, it is not known whether inflammation may be associated with cognition in the present sample. Future work is needed to determine whether plant-based diets reduce inflammation, and whether this may mediate any improvements in cognition.

Indirect evidence from studies examining Western and Mediterranean diets has also suggested that a plant-based diet may be important for health and cognition. The Western dietmarked by high fat and sugar intake - for example, may exert many of its detrimental effects on 
cognition through saturated fat consumption (51-58). Importantly, the primary source of saturated fat in the Western diet is animal products such as red meat and dairy (59). Thus, it is possible that the Western diet may impair health and cognition in part through high intakes of red meat and dairy, which are consumed less by those eating a more plant-based diet (5).

In a similar vein, a major component of the Mediterranean diet responsible for its benefits is reduced meat consumption $(60,61)$ - in fact, when directly compared, meat intake alone has been shown to account for more variance in cognitive performance than does the standard Mediterranean diet score (62). Another consistent finding is that the Mediterranean diet components encapsulating fruit, vegetable, and whole grain consumption — all of which are high in fiber and ubiquitous in plant-based diets_-are important predictors of improved health and global cognition (63-66). Interestingly, some argue that the consumption of olive oil plays an essential role in the benefits of the Mediterranean diet due to its uniquely high monounsaturated fat content, but results are mixed $(43,44)$. In the present data, a secondary analysis indicated that monounsaturated fat had no relation to any of the cognitive outcomes, and Bayes factors supported this lack of effect. The present results, combined with prior conflicting results $(43,44)$, could be taken to suggest that monounsaturated fat intake may not be as important for cognition as the other aforementioned aspects of the Mediterranean diet. Thus, the benefits of a Mediterranean diet may be in part mediated by a decrease in meat intake, and an increase in vegetable and whole grain intake, which are in line with a shift towards a more plant-based diet.

The present study has limitations that should be noted. First, it was not possible to assess actual plant-based food consumption, as the data consisted of macronutrient information rather than food group information. In other datasets, increased consumption of plant-based foods relative to animal-based foods has been strongly correlated with the macronutrient profile we 
examined in this study (i.e., high in fiber, high in polyunsaturated fat, low in saturated fat, and low in protein $(5,11,12)$, but a limitation of this study is that the dietary data were macronutrient reports rather than actual plant and nonplant food consumption. Finally, it should be stressed that all associations were cross-sectional, which precludes inference or discussion of cause and temporal precedence. Reverse causality is certainly possible in this association; for example, people with better cognitive function may be better able to adhere to a diet touted as healthy (i.e., one high in fruits and vegetables), or a third factor may have led to increases in both cognitive performance and a diet more consistent with a plant-based diet. Although the included covariates may suggest that the observed associations were not entirely driven by an overall healthier lifestyle, future experimental work should attempt to establish causal relationships of these effects.

In sum, these results suggest that plant-based diets are related to more than just physical health — they are related to better cognitive abilities as well. If it is found that plant-based diets are indeed able to improve cognition, plant-based diets could prove to be an easily implemented and high adherence (11) intervention for cognitive impairment. 


\section{References}

1. Mokdad AH, Marks JS, Stroup DF, Gerberding JL. Actual causes of death in the United States, 2000. JAMA J Am Med Assoc [Internet]. 2004;291(10):1238-45. Available from: http://jama.jamanetwork.com/article.aspx?doi=10.1001/jama.1993.03510180077038

2. Murray CJL, Atkinson C, Bhalla K, Birbeck G, Burstein R, Chou D, et al. The state of US health, 1990-2010: burden of diseases, injuries, and risk factors. JAMA [Internet]. 2013 Aug 14 [cited 2018 Oct 3];310(6):591-608. Available from: http://www.ncbi.nlm.nih.gov/pubmed/23842577

3. Grimm KA, Blanck HM, Scanlon KS, Moore L V., Grummer-Strawn LM, Foltz JL. StateSpecific Trends in Fruit and Vegetable Consumption Among Adults - United States, 2000 - 2009. Morb Mortal Wkly Rep [Internet]. 2010 [cited 2019 Jul 2];1125-30. Available from: https:/www.cdc.gov/mmwr/PDF/wk/mm5935.pdf

4. Nishida C, Uauy R, Kumanyika S, Shetty P. The Joint WHO/FAO Expert Consultation on diet, nutrition and the prevention of chronic diseases: process, product and policy implications. Public Health Nutr. 2004;7(1a):245-50.

5. Turner-McGrievy GM, Wirth MD, Shivappa N, Wingard EE, Fayad R, Wilcox S, et al. Randomization to plant-based dietary approaches leads to larger short-term improvements in Dietary Inflammatory Index scores and macronutrient intake compared with diets that contain meat. Nutr Res [Internet]. 2015 Feb 1 [cited 2018 Mar 18];35(2):97-106. Available from: https:/www.sciencedirect.com/science/article/pii/S027153171400267X

6. Barnard ND, Cohen J, Jenkins DJA, Turner-McGrievy G, Gloede L, Jaster B, et al. A lowfat vegan diet improves glycemic control and cardiovascular risk factors in a randomized clinical trial in individuals with type 2 diabetes. Diabetes Care [Internet]. 2006 [cited 2018 
Mar 6];29(8):1777-83. Available from:

http://care.diabetesjournals.org/content/diacare/29/8/1777.full.pdf

7. Barnard ND, Cohen J, Jenkins DJA, Turner-McGrievy G, Gloede L, Green A, et al. A low-fat vegan diet and a conventional diabetes diet in the treatment of type 2 diabetes: A randomized, controlled, 74-wk clinical trial. Am J Clin Nutr [Internet]. 2009 May 1 [cited 2018 Mar 6];89(5):1588S-1596S. Available from: https://academic.oup.com/ajcn/article/89/5/1588S/4596944

8. Barnard ND, Scialli AR, Turner-McGrievy G, Lanou AJ, Glass J. The effects of a low-fat, plant-based dietary intervention on body weight, metabolism, and insulin sensitivity. Am J Med [Internet]. 2005 [cited 2017 Aug 7];118(9):991-7. Available from:

http://www.pcrm.org/sites/default/files/pdfs/health/medstudents/The effects of a low-fat plant-based dietary intervention on body weight metabolism and insulin sensitivity .pdf

9. Hu FB. Plant-based foods and prevention of cardiovascular disease: an overview. Am J Clin Nutr [Internet]. 2003 Sep 1 [cited 2018 Mar 6];78:544S-551S. Available from: https://academic.oup.com/ajcn/article/78/3/544S/4689995

10. Pistollato F, Battino M. Role of plant-based diets in the prevention and regression of metabolic syndrome and neurodegenerative diseases. Trends Food Sci Technol [Internet]. 2014 [cited 2017 Sep 25];40:62-81. Available from: https://ac.elscdn.com/S0924224414001642/1-s2.0-S0924224414001642-main.pdf?_tid=b02971eca24b-11e7-8b5a-

00000aab0f26\&acdnat $=1506383342 \_$e5559c40a1cd2c6152f1d5a3bf04b37b

11. Barnard ND, Gloede L, Cohen J, Jenkins DJA, Turner-McGrievy G, Green AA, et al. A low-fat vegan diet elicits greater macronutrient changes, but is comparable in adherence 
and acceptability, compared with a more conventional diabetes diet among individuals with type 2 diabetes. J Am Diet Assoc [Internet]. 2009 [cited 2018 Mar 6];109(2):263-72. Available from: http://jandonline.org/article/S0002-8223(08)02042-7/pdf

12. Clarys P, Deliens T, Huybrechts I, Deriemaeker P, Vanaelst B, De Keyzer W, et al. Comparison of nutritional quality of the vegan, vegetarian, semi-vegetarian, pescovegetarian and omnivorous diet. Nutrients [Internet]. 2014 Mar 24 [cited 2018 Mar 18];6(3):1318-32. Available from: http://www.mdpi.com/2072-6643/6/3/1318

13. Lindseth GN, Lindseth PD, Jensen WC, Petros T V, Helland BD, Fossum DL. Dietary effects on cognition and pilots' flight performance. Int J Aviat Psychol [Internet]. 2011 [cited 2018 Jun 11];21(3):269-82. Available from:

http://www.ncbi.nlm.nih.gov/pubmed/29353985

14. van der Zwaluw NL, van de Rest O, Tieland M, Adam JJ, Hiddink GJ, van Loon LJC, et al. The impact of protein supplementation on cognitive performance in frail elderly. Eur $\mathbf{J}$ Nutr [Internet]. 2014 Apr 18 [cited 2018 Jun 11];53:803-12. Available from: http://link.springer.com/10.1007/s00394-013-0584-9

15. Gu Y, Vorburger RS, Gazes Y, Habeck CG, Stern Y, Luchsinger JA, et al. White matter integrity as a mediator in the relationship between dietary nutrients and cognition in the elderly. Ann Neurol [Internet]. 2016 [cited 2017 Sep 8];79(6):1014-25. Available from: https://www.ncbi.nlm.nih.gov/pmc/articles/PMC4884180/pdf/nihms783561.pdf

16. Khan NA, Raine LB, Drollette ES, Scudder MR, Kramer AF, Hillman CH. Dietary Fiber Is Positively Associated with Cognitive Control among Prepubertal Children. J Nutr [Internet]. 2015 Jan 1 [cited 2017 Aug 31];145:143-9. Available from: https://academic.oup.com/jn/article/145/1/143/4585770 
17. Okereke OI, Rosner BA, Kim DH, Kang JH, Cook NR, Manson JE, et al. Dietary fat types and 4-year cognitive change in community-dwelling older women. Ann Neurol [Internet]. 2012 Jul 1 [cited 2017 Aug 31];72:124-34. Available from:

http://doi.wiley.com/10.1002/ana.23593

18. Solfrizzi V, Colacicco AM, D’Introno A, Capurso C, Torres F, Rizzo C, et al. Dietary intake of unsaturated fatty acids and age-related cognitive decline: A 8.5-year follow-up of the Italian Longitudinal Study on Aging. Neurobiol Aging [Internet]. 2006 [cited 2017 Sep 8];27:1694-704. Available from: http://ac.els-cdn.com/S0197458005003039/1-s2.0S0197458005003039-main.pdf?_tid=000443b2-94dd-11e7-ad1d00000aacb35d\&acdnat=1504906436_5c82b5457754aa847e789b6c71664fee

19. Beilharz JE, Maniam J, Morris MJ. Diet-Induced Cognitive Deficits: The Role of Fat and Sugar, Potential Mechanisms and Nutritional Interventions. Nutrients [Internet]. 2015 Aug [cited 2016 Oct 6];7(8):6719-38. Available from: http://www.ncbi.nlm.nih.gov/pubmed/26274972

20. Morris MC, Evans DA, Bienias JL, Tangney CC, Wilson RS. Dietary fat intake and 6year cognitive change in an older biracial community population. Neurology [Internet]. 2004 May 11 [cited 2017 Aug 31];62:1573-9. Available from:

http://www.ncbi.nlm.nih.gov/pubmed/15136684\%5Cnhttps:/www.neurology.org/content/ 62/9/1573.full

21. Eskelinen MH, Ngandu T, Helkala EL, Tuomilehto J, Nissinen A, Soininen H, et al. Fat intake at midlife and cognitive impairment later in life: A population-based CAIDE study. Int J Geriatr Psychiatry. 2008;23(7):741-7.

22. Gibson EL, Barr S, Jeanes YM. Habitual fat intake predicts memory function in younger 
women. Front Hum Neurosci [Internet]. 2013;7(December):838. Available from: http://www.pubmedcentral.nih.gov/articlerender.fcgi?artid=3858814\&tool=pmcentrez\&re ndertype $=$ abstract

23. Gates NJ, Sachdev PS, Fiatarone Singh MA, Valenzuela M. Cognitive and memory training in adults at risk of dementia: A systematic review. BMC Geriatr. 2011;11(55).

24. Insel K, Morrow D, Brewer B, Figueredo A. Executive function, working memory, and medication adherence among older adults. Journals Gerontol Ser B, Psychol Sci Soc Sci. 2006;61:P102-7.

25. Mirelman A, Herman T, Brozgol M, Dorfman M, Sprecher E, Schweiger A, et al. Executive function and falls in older adults: New findings from a five-year prospective study link fall risk to cognition. PLoS One. 2012;7(6):e40297.

26. US Department of Health and Human Services C for DC and P. About the National Health and Nutrition Examination Survey. https//www.cdc gov/nchs/nhanes.htm (accessed June 2017). 2017;

27. NHANES 2011-2012: Cognitive Functioning Data Documentation, Codebook, and Frequencies [Internet]. [cited 2019 Jun 4]. Available from: https://wwwn.cdc.gov/Nchs/Nhanes/2011-2012/CFQ_G.htm

28. Yang Y, Shields GS, Guo C, Liu Y. Executive function performance in obesity and overweight individuals: A meta-analysis and review. Neurosci Biobehav Rev. $2018 ; 84: 225-44$.

29. Karr JE, Hofer SM, Iverson GL, Garcia-Barrera MA. Examining the latent structure of the Delis-Kaplan Executive Function System. Arch Clin Neuropsychol. 2018 May;

30. Salthouse TA. The processing-speed theory of adult age differences in cognition. Psychol 
Rev [Internet]. 1996 Jul [cited 2018 Oct 1];103(3):403-28. Available from: http://www.ncbi.nlm.nih.gov/pubmed/8759042

31. Lehtisalo J, Lindström J, Ngandu T, Kivipelto M, Ahtiluoto S, Ilanne-Parikka P, et al. Association of long-term dietary fat intake, exercise, and weight with later cognitive function in the Finnish Diabetes Prevention Study. J Nutr Health Aging [Internet]. 2016 Feb 7 [cited 2017 Aug 31];20(2):146-54. Available from: http://link.springer.com/10.1007/s12603-015-0565-1

32. Abdi H, Williams LJ. Principal component analysis. Wiley Interdiscip Rev Comput Stat. 2010;2(4):433-59.

33. Goldfarb E V, Shields GS, Daw ND, Slavich GM, Phelps EA. Low lifetime stress exposure is associated with reduced stimulus - response memory. [cited $2017 \mathrm{Jul} 13$ ]; Available from: http://learnmem.cshlp.org/content/24/4/162.full.pdf

34. Beeri MS, Schmeidler J, Sano M, Wang J, Lally R, Grossman H, et al. Age, gender, and education norms on the CERAD neuropsychological battery in the oldest old. Neurology. 2006;67(6):1006-10.

35. Allan JL, McMinn D, Daly M. A bidirectional relationship between executive function and health behavior: Evidence, implications, and future directions. Front Neurosci. 2016 Aug 23;10(AUG):386.

36. Bryan J, Luszcz MA. Measurement of executive function: considerations for detecting adult age differences. J Clin Exp Neuropsychol [Internet]. 2000 Feb [cited 2020 Mar 2];22(1):40-55. Available from: http://www.ncbi.nlm.nih.gov/pubmed/10649544

37. Johnson AS, Flicker LJ, Lichtenberg PA. Reading ability mediates the relationship between education and executive function tasks. J Int Neuropsychol Soc [Internet]. 2006 
Jan [cited 2020 Mar 2];12(1):64-71. Available from:

http://www.ncbi.nlm.nih.gov/pubmed/16433945

38. Van Der Elst W, Van Boxtel MPJ, Van Breukelen GJP, Jolles J. The stroop color-word test: Influence of age, sex, and education; and normative data for a large sample across the adult age range [Internet]. Vol. 13, Assessment. 2006 [cited 2020 Mar 2]. p. 62-79.

Available from: http://www.ncbi.nlm.nih.gov/pubmed/16443719

39. Jeffreys H. Theory of probability. 3rd ed. Oxford, England: Clarendon; 1961. 1-447 p.

40. Luck T, Pabst A, Rodriguez FS, Schroeter ML, Witte V, Hinz A, et al. Age-, sex-, and education-specific norms for an extended CERAD neuropsychological Assessment Battery-results from the population-based LIFE-Adult-Study. Neuropsychology. 2018;32(4):461-75.

41. Hoyer WJ, Stawski RS, Wasylyshyn C, Verhaeghen P. Adult Age and Digit Symbol Substitution Performance: A Meta-Analysis. 2004;

42. Willett W, Stampfer MJ. Total energy intake: implications for epidemiologic analyses. Am J Epidemiol [Internet]. 1986 Jul [cited 2018 Oct 3];124(1):17-27. Available from: http://www.ncbi.nlm.nih.gov/pubmed/3521261

43. Hu FB. The Mediterranean Diet and Mortality - Olive Oil and Beyond. N Engl J Med [Internet]. 2003 [cited 2018 Feb 7];348(26):2595-6. Available from: http://www.nejm.org/doi/abs/10.1056/NEJMp030069

44. Martínez-Lapiscina EH, Clavero P, Toledo E, Estruch R, Salas-Salvadó J, San Julián B, et al. Mediterranean diet improves cognition: The PREDIMED-NAVARRA randomised trial. J Neurol Neurosurg Psychiatry [Internet]. 2013 Dec [cited 2016 Nov 27];84(12):1318-25. Available from: http://www.ncbi.nlm.nih.gov/pubmed/23670794 
45. Shields GS, Moons WG, Slavich GM. Inflammation, self-regulation, and health: An immunologic model of self-regulatory failure. Perspect Psychol Sci. 2017;12:588-612.

46. Ozawa M, Shipley M, Kivimaki M, Singh-Manoux A, Brunner EJ. Dietary pattern, inflammation and cognitive decline: The Whitehall II prospective cohort study. Clin Nutr [Internet]. 2017 [cited 2017 Sep 8];36:506-12. Available from: http://ac.elscdn.com/S0261561416000352/1-s2.0-S0261561416000352-main.pdf?_tid=40881c4694de-11e7-84f400000aab0f01\&acdnat=1504906974_0885f7f9a95a5781bf8b74ee6b63c2a6

47. Kiecolt-Glaser JK. Stress, food, and inflammation: Psychoneuroimmunology and nutrition at the cutting edge. Psychosom Med [Internet]. 2010 May [cited 2017 Jul 18];72(4):3659. Available from: http://www.ncbi.nlm.nih.gov/pubmed/20410248

48. King DE. Dietary fiber, inflammation, and cardiovascular disease. Mol Nutr Food Res. 2005;49:594-600.

49. Steel DM, Whitehead AS. The major acute phase reactants: C-reactive protein, serum amyloid P component and serum amyloid A protein. Immunol Today [Internet]. 1994 Feb [cited 2018 Oct 1];15(2):81-8. Available from:

http://www.ncbi.nlm.nih.gov/pubmed/8155266

50. Sobesky JL, Barrientos RM, De May HS, Thompson BM, Weber MD, Watkins LR, et al. High-fat diet consumption disrupts memory and primes elevations in hippocampal IL-1 $\beta$, an effect that can be prevented with dietary reversal or IL-1 receptor antagonism. Brain Behav Immun [Internet]. 2014 [cited 2017 Oct 10];42:22-32. Available from: https://ac.els-cdn.com/S0889159114001822/1-s2.0-S0889159114001822main.pdf?_tid=3f5ba166-ae0c-11e7-be17- 
00000aacb35d\&acdnat=1507675508_4236ec5af759748f62d7889dede00f9a

51. Greenwood CE, Winocur G. Glucose treatment reduces memory deficits in young adult rats fed high-fat diets. Neurobiol Learn Mem [Internet]. 2001 Mar 1 [cited 2018 Feb 6];75:179-89. Available from:

https://www.sciencedirect.com/science/article/pii/S1074742700939649

52. Greenwood CE, Winocur G. High-fat diets, insulin resistance and declining cognitive function. Neurobiol Aging. 2005;26(1):42-5.

53. Winocur G, Greenwood CE. Studies of the effects of high fat diets on cognitive function in a rat model. Neurobiol Aging [Internet]. 2005 Dec 1 [cited 2018 Feb 6];26:46-9. Available from:

https://www.sciencedirect.com/science/article/pii/S0197458005002642?via\%253Dihub

54. Greenwood CE, Winocur G. Learning and memory impairment in rats fed a high saturated fat diet. Behav Neural Biol [Internet]. 1990 [cited 2018 Feb 6];53:74-87. Available from: https://ac.els-cdn.com/016310479090831P/1-s2.0-016310479090831Pmain.pdf?_tid=17bc15c2-0b87-11e8-b5ad00000aacb362\&acdnat $=1517953728 \_c 46 a 852400955$ cdca50f703f8cdcaff2

55. Boitard C, Cavaroc A, Sauvant J, Aubert A, Castanon N, Layé S, et al. Impairment of hippocampal-dependent memory induced by juvenile high-fat diet intake is associated with enhanced hippocampal inflammation in rats. Brain Behav Immun [Internet]. 2014 Aug 1 [cited 2018 Feb 6];40:9-17. Available from: https://www.sciencedirect.com/science/article/pii/S0889159114000713

56. Boitard C, Parkes SL, Cavaroc A, Tantot F, Castanon N, Layé S, et al. Switching Adolescent High-Fat Diet to Adult Control Diet Restores Neurocognitive Alterations. 
Front Behav Neurosci [Internet]. 2016;10(December):225. Available from: http://www.ncbi.nlm.nih.gov/pubmed/27917115\%5Cnhttp://www.pubmedcentral.nih.gov/ articlerender.fcgi?artid=PMC5116459

57. Freeman LR, Haley-Zitlin V, Rosenberger DS, Granholm A-C. Damaging effects of a high-fat diet to the brain and cognition: A review of proposed mechanisms. Nutr Neurosci [Internet]. 2014 Nov [cited 2016 Nov 27];17(6):241-51. Available from: http://www.tandfonline.com/doi/full/10.1179/1476830513Y.0000000092

58. Francis H, Stevenson R. The longer-term impacts of Western diet on human cognition and the brain. Appetite [Internet]. 2013 Apr 1 [cited 2018 Feb 6];63:119-28. Available from: https:/www.sciencedirect.com/science/article/pii/S0195666312005144

59. Hu FB, Stampfer MJ, Manson JE, Ascherio A, Colditz GA, Speizer FE, et al. Dietary saturated fats and their food sources in relation to the risk of coronary heart disease in women. Am J Clin Nutr [Internet]. 1999;70:1001-8. Available from: http://www.ncbi.nlm.nih.gov/pubmed/10584044\%5Cnhttp://ajcn.nutrition.org/content/70/ 6/1001.full.pdf

60. Gu Y, Brickman AM, Stern Y, Habeck CG, Razlighi QR, Luchsinger JA, et al. Mediterranean diet and brain structure in a multiethnic elderly cohort. Neurology [Internet]. 2015 [cited 2018 Oct 2];85(20):1744-51. Available from: http://surfer.nmr.mgh.

61. Hardman RJ, Kennedy G, Macpherson H, Scholey AB, Pipingas A. Adherence to a Mediterranean-Style Diet and Effects on Cognition in Adults: A Qualitative Evaluation and Systematic Review of Longitudinal and Prospective Trials. Front Nutr [Internet]. 2016 [cited 2018 Oct 2];3:1. Available from: www.frontiersin.org 
62. Titova OE, Ax E, Brooks SJ, Sjögren P, Cederholm T, Kilander L, et al. Mediterranean diet habits in older individuals: Associations with cognitive functioning and brain volumes. Exp Gerontol [Internet]. 2013 [cited 2017 Sep 8];48:1443-8. Available from: http://ac.els-cdn.com/S0531556513003033/1-s2.0-S0531556513003033main.pdf?_tid=8a5a137a-94e2-11e7-84f400000aab0f01\&acdnat=1504908817_92811cdfee9a4db07d4e1505f1d5898a

63. Staubo SC, Aakre JA, Vemuri P, Syrjanen JA, Mielke MM, Geda YE, et al. Mediterranean diet, micronutrients and macronutrients, and MRI measures of cortical thickness. Alzheimer's Dement [Internet]. 2017 [cited 2017 Sep 8];13:168-77. Available from: http://dx.doi.org/10.1016/j.jalz.2016.06.2359

64. Samieri C, Grodstein F, Rosner BA, Kang JH, Cook NR, Manson JE, et al. Mediterranean diet and cognitive function in older age. Epidemiology [Internet]. 2013 Jul [cited 2018 May 1];24(4):490-9. Available from: http://www.ncbi.nlm.nih.gov/pubmed/23676264

65. Morris MC, Evans DA, Tangney CC, Bienias JL, Wilson RS. Associations of vegetable and fruit consumption with age-related cognitive change. Neurology [Internet]. 2006 Oct 24 [cited 2018 Oct 3];67(8):1370-6. Available from:

http://www.ncbi.nlm.nih.gov/pubmed/17060562

66. Qin B, Adair LS, Plassman BL, Batis C, Edwards LJ, Popkin BM, et al. Dietary Patterns and Cognitive Decline Among Chinese Older Adults. Epidemiology [Internet]. 2015 Sep [cited 2018 Oct 3];26(5):758-68. Available from: http://www.ncbi.nlm.nih.gov/pubmed/26133024

67. Moubarac JC, Batal M, Louzada ML, Martinez Steele E, Monteiro CA. Consumption of ultra-processed foods predicts diet quality in Canada. Appetite. 2017 Jan 1;108:512-20. 